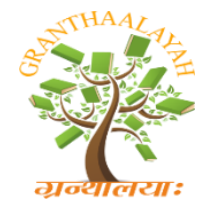

$$
\begin{gathered}
\text { INTERNATIONAL JOURNAL OF RESEARCH - } \\
\text { GRANTHAALAYAH } \\
\text { A knowledge Repository }
\end{gathered}
$$

Science

\title{
STUDY AND ANALYSIS OF PERMANENT MAGNET DC MOTORS WITH VARIOUS PARAMETERS
}

\author{
Dr. S. K. Mahobia*1 \\ ${ }^{* 1}$ Assistant Professor, Department of Physics, Rewa Engineering College, Rewa (M.P.). India
}

DOI: https://doi.org/10.29121/granthaalayah.v5.i2.2017.1716

\begin{abstract}
The permanent magnet type DC motors are used in various applications as heater, wiper. DC motors are any of a class of electrical machines that converts direct current electrical power into mechanical power. The DC motor has important role in moving machine because of mostly use in the industry appliances. The speed control of DC motor is increasingly getting sophisticated and precise. The Speed of the DC motor is controlled by with the help of controlling the stator winding voltage. There are various methods of speed control of DC drives namely field control.
\end{abstract}

Keywords: Rectifier; Permanent Magnet; DC Motor; Stator.

Cite This Article: Dr. S. K. Mahobia. (2017). "STUDY AND ANALYSIS OF PERMANENT MAGNET DC MOTORS WITH VARIOUS PARAMETERS." International Journal of Research - Granthaalayah, 5(2), 151-155. 10.29121/granthaalayah.v5.i2.2017.1716.

\section{Introduction}

DC motors are the first type widely used, since they could be powered from existing directcurrent lighting power distribution systems. A DC motor's speed can be controlled over a wide range, using either a variable supply voltage or by changing the strength of current in its field windings. Small DC motors are used in tools, toys, and appliances. The universal motor can operate on direct current but is a lightweight motor used for portable power tools and appliances. Larger DC motors are used in propulsion of electric vehicles or in drives for steel rolling mills.

\section{Permanent Magnet Stators}

PM fields (stators) are convenient in miniature motors to eliminate the power consumption of the field winding. Most larger DC motors are of the "dynamo" type, which have stator windings. Historically, PMs could not be made to retain high flux if they were disassembled; field windings were more practical to obtain the needed amount of flux. However, large PMs are costly, as well as dangerous and difficult to assemble; this favors wound fields for large machines. 


\section{Single-Phase Rectifiers}

\subsection{Half-Wave Rectification}

Half-wave rectification requires a single diode in a single-phase supply, or three in a three-phase supply. Rectifiers yield a unidirectional but pulsating direct current; half-wave rectifiers produce far more ripple than full-wave rectifiers, and much more filtering is needed to eliminate harmonics of the $\mathrm{AC}$ frequency from the output.
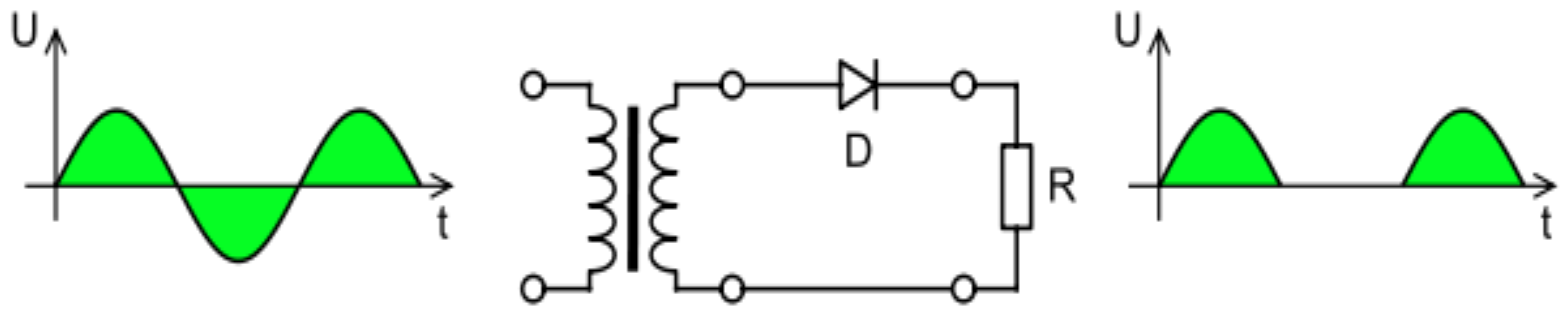

Figure 1: Half-wave rectifier

\subsection{Full-Wave Rectification}

Single semiconductor diodes, double diodes with common cathode or common anode, and fourdiode bridges, are manufactured as single components.
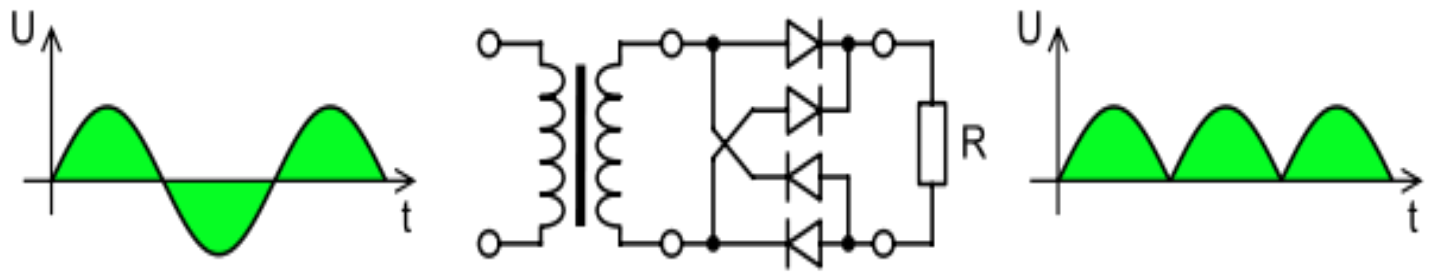

Figure 2: Full-wave rectifier using 4 diodes

For single-phase AC, if the transformer is center-tapped, then two diodes back-to-back (cathodeto-cathode or anode-to-anode, depending upon output polarity required) can form a full-wave rectifier. Twice as many turns are required on the transformer secondary to obtain the same output voltage than for a bridge rectifier, but the power rating is unchanged.
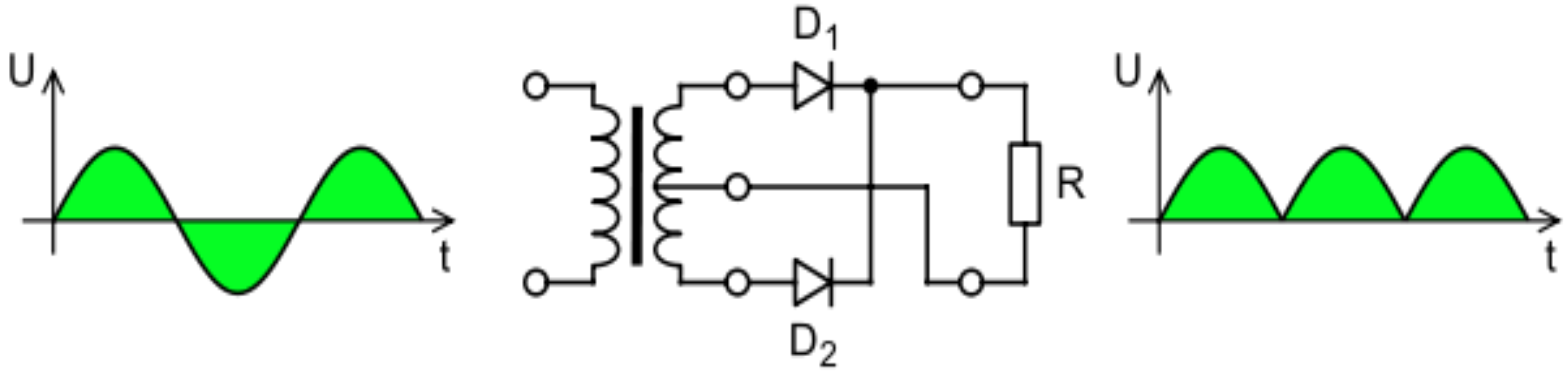

Figure 3: Full-wave rectifier using a center tap transformer and 2 diodes 


\section{Results and Discussion}

Table 1: Voltage and R.P.M. using of Permanent magnet type D.C. Motor with 1 ampere

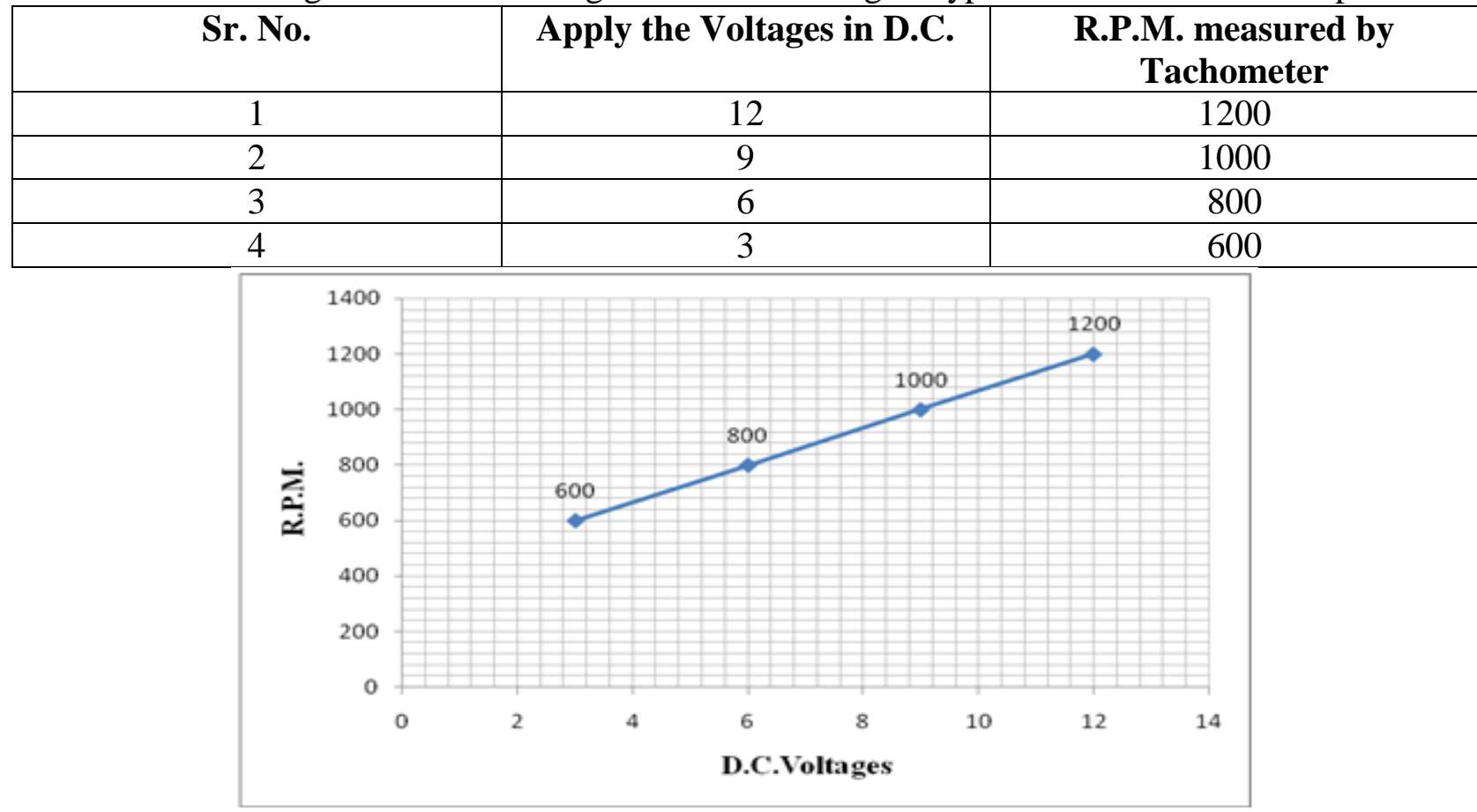

Figure 4: Voltage and R.P.M. using of Permanent magnet type D.C. Motor with 1 ampere

Table 2: Voltage and R.P.M. using of Permanent magnet type D.C. Motor with 2 ampere

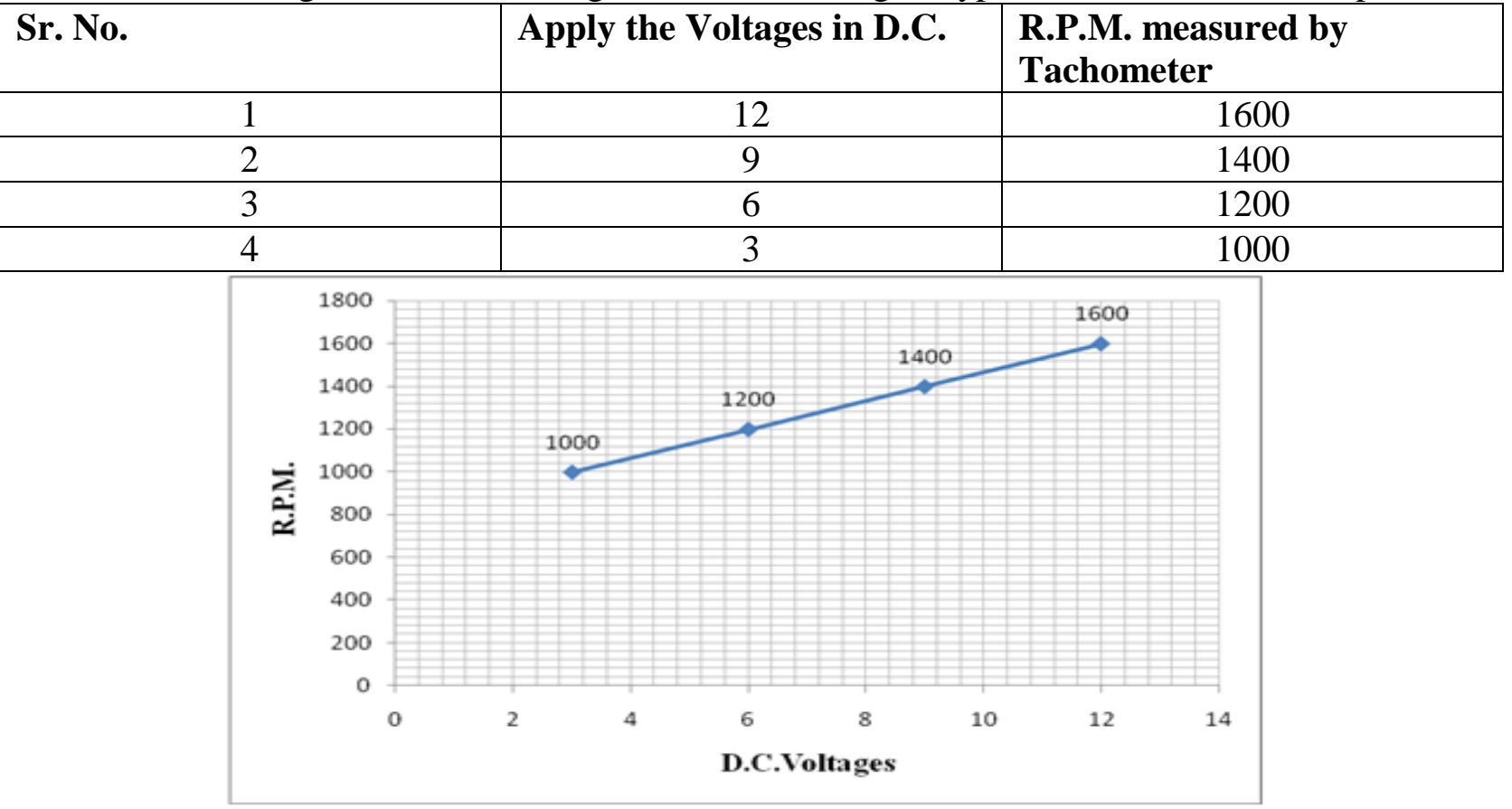

Figure 5: Voltage and R.P.M. using of Permanent magnet type D.C. Motor with 2 amperes 
Table 3: Voltage and R.P.M. using of Permanent magnet type D.C. Motor with 3 amperes

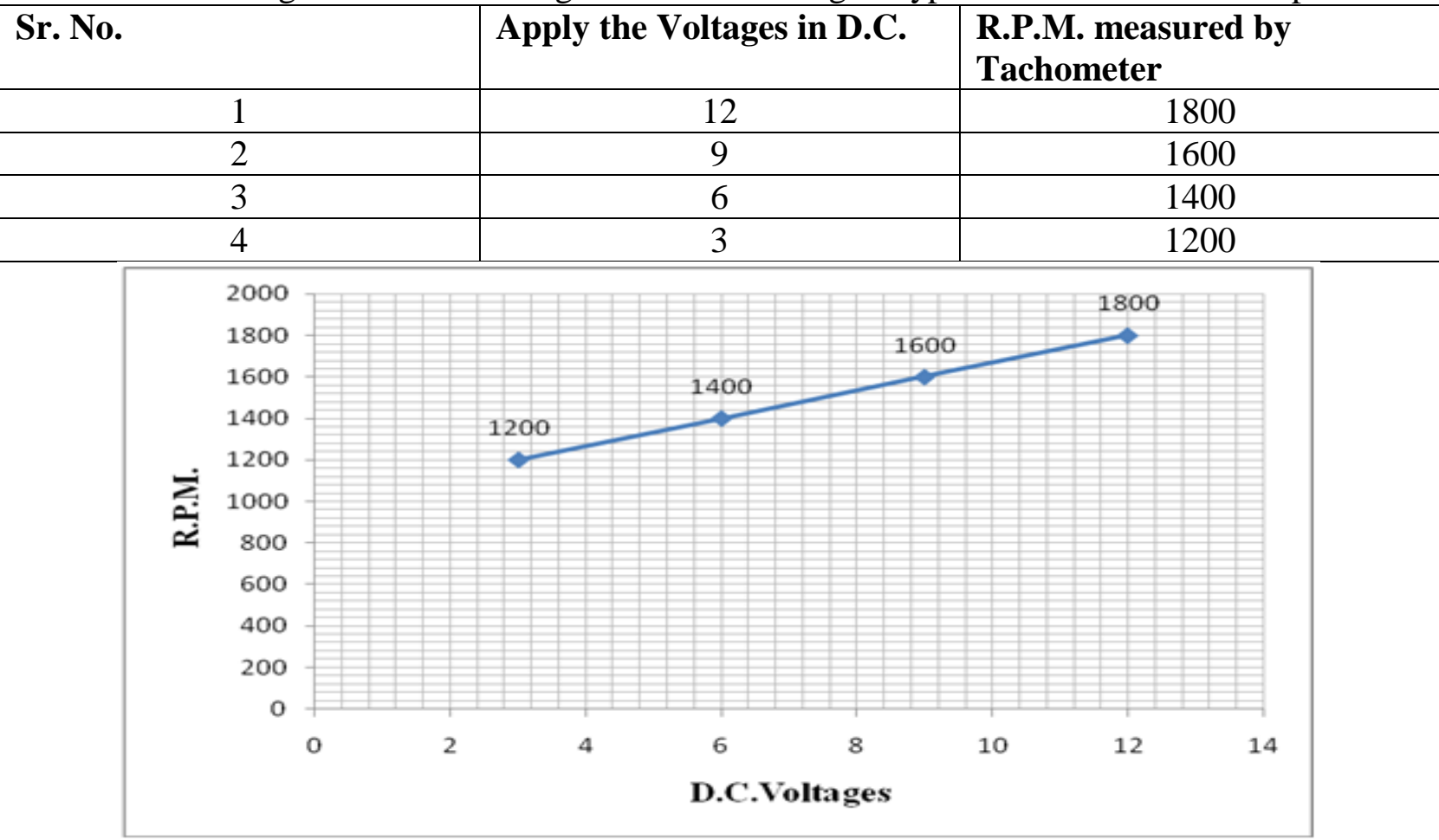

Figure 6: Voltage and R.P.M. using of Permanent magnet type D.C. Motor with 3 ampere

Table 4: Voltage and R.P.M. using of Permanent magnet type D.C. Motor with 5 ampere

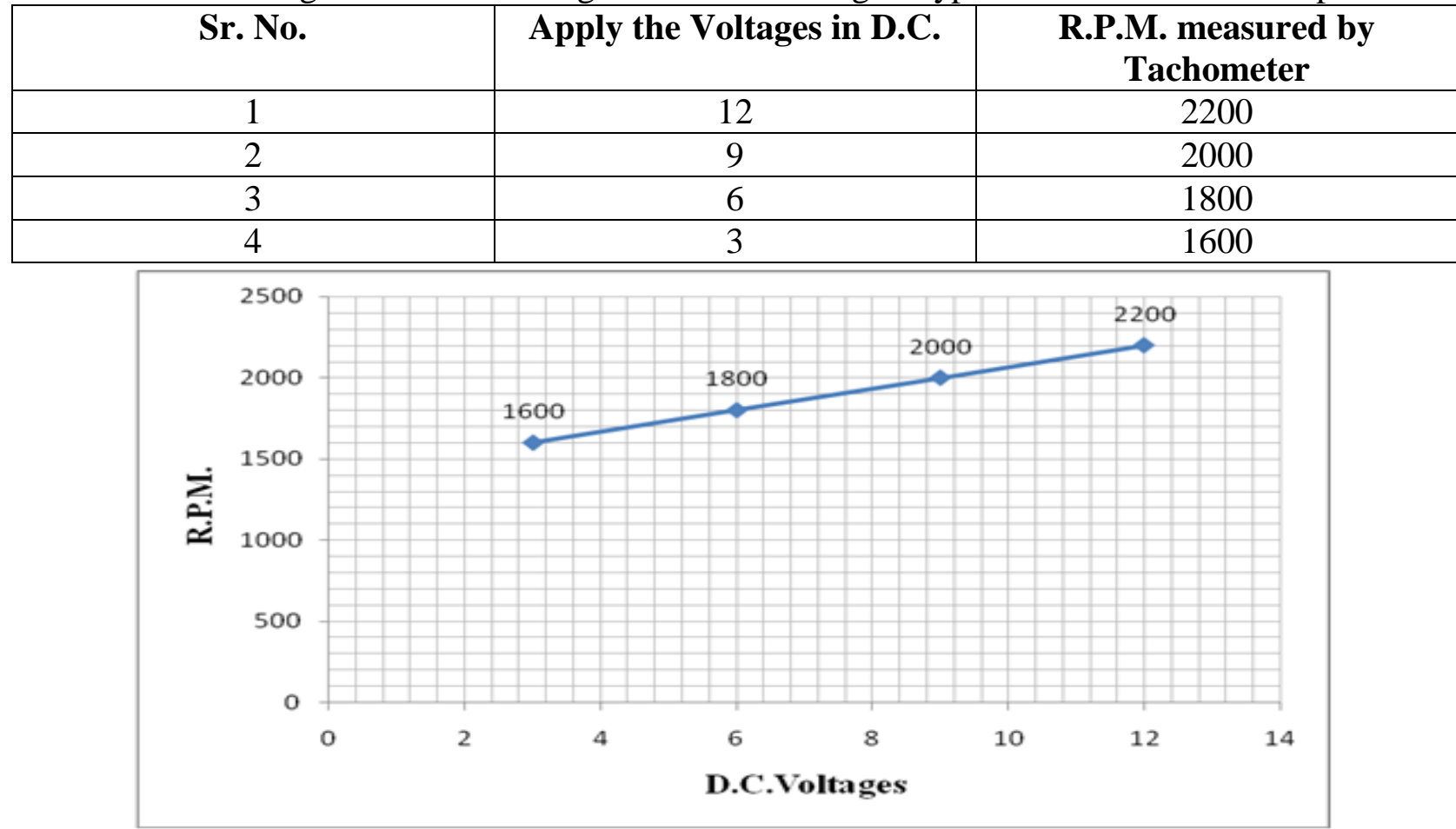

Figure 7: Voltage and R.P.M. using of Permanent magnet type D.C. Motor with 5 amperes 


\section{Conclusions}

During these this study, we are finding out the various R.P.M. using of speed control. Which is varies the voltage. We are obtaining the Maximum 2200 R.P.M. By Permanent magnet type D.C. Motor by using of Apply the Voltages are 12 D.C. with 5 amperes.

\section{References}

[1] A.W. Kelley and W.F. Yadusky, Phase-controlled rectifier linecurrent harmonics and power factor as a function of firing angle and output filter inductance, Proc. APEC'90.

[2] Eupec, Rectifier diode D 2601N, BIP AC / SM PB, 2002-05-31, Eupec Data Sheet.

[3] Eupec, Phase control thyristor T 2871N, BIP AM / SM PB, 2002-04- 07, Eupec Data Sheet.

[4] F. Blaabjerg, F. Iov, T. Kerekes, R. Teodorescu, ,Trends in power electronics and control of renewable energy systems, Power Electronics and Motion Control Conference (EPE/PEMC), 2010, pp. K-1 - K-19.

[5] Maria IMECS, Csaba SZABO, Ioan Iov INCZE, Modeling and simulation of controlled bidirectional power electronic converters in a DC energy distribution line with AC grid- and motorside active filtering, Power Electronics and Applications, 2007 ,pp.1-10.

[6] R.S. Ramshaw, Power Electronics Semiconductor Switches (Chapman \& Hall, London, 1993).

[7] P.C. Sen, Power Electronics (Tata McGraw-Hill, 1988).

[8] J. Schaefer, Rectifier Circuits: Theory and Design (Wiley, 1965).

[9] G.J. Wakileh, Power Systems Harmonics (Springer, 2001).

[10] M.H. Rashid (ed.), Power Electronics Handbook (Academic Press, 2001) 